Longer term studies are necessary to determine whether treatment with sulphasalazine can prevent late complications such as ankylosis and whether it can induce prolonged remissions of the disease.

\section{References}

1 Peppercorn MA. Sulfasalazine: pharmacology, clinical use, toxicity and related new drug development. Ann Intern Med 1984;3:377-86.

2 McConley B, Amos RS, Durham S, Forster PJC, Hitball S, Walsh L. Sulphasalazine in rheumatoid arthritis. BrMed f 1980;280:442-4.

3 Pullar T, Capell H. Sulphasalazine: a "new" antirheumatic drug. Br $\mathcal{f}$ Rheumatol 1984;23:26-8.

4 Amor B, Kahan A, Dougados M, Delrieu F. Sulfasalazine and ankylosing spondylitis. Ann Intern Med 1984;101:878.

5 Ebringer RW, Cawdell DR, Cowling P, Ebringer A. Sequential studies in ankylosing spondylitis. Association of Klebsiella pneumoniae with active disease. Ann Rheum Dis 1979;37:146-51.

6 Alemanni $M$, Dougados M, Abadia R, et al. Ileocolonoscopy and bowel histology in patients with seronegative spondyloarthropathies. European League Against Rheumatism Symposium (in press).

Mielants $R$, Veys EM. Inflammation of the ileum in patients with B27 positive reactive arthritis. Lancet 1984; iv: 288 .

8 Bennett PH, Burch TA. New York symposium on population studies in the rheumatic diseases: new diagnostic criteria. In: Rodnan GF, ed. Bulletin on the rheumatic diseases. New York: Arthritis Foundation, 1967:453-8.

9 Feltelius N, Hallgren R. Sul:4salazine in ankylosing spondylitis. Ann Rheum Dis 1986;45:396-9.

10 Surawiz CM Meisel JL, Ylvisaker T, Saunders DR Rubin CE. Rectal biopsy in the diagnosis of Crohn's disease: value of multiple biopsies and serial sectioning. Gastroenterology 1981;80: $66-72$.

11 European League Against Rheumatism. Guidelines for the clinical investigation of drugs used in rheumatic diseases. Copenhagen: World Health Organisation, 1985:7-11

12 Azadkhan AK, Truelove SC, Aronson JK. The disposition and metabolism of sulphasalazine (salicylazosulphapyridine) in man. Br f Clin Pharmacol 1982;13:523-8.

13 Ebringer A. The cross tolerance hypothesis, HLA B27 and ankylosing spondylitis. Br $\mathcal{F}$ Rheumatol 1983;22(suppl 2):53-66.

14 Delamere JP, Farr M, Grindulis KA. Sulphasalazine induced selective IgA deficiency in rheumatoid arthritis. Br Med f 1983;286:1547-8.

15 Savilahti E. Sulphasalazine induced immunodeficiency. Br Med f 1983;287:759.

16 Bax DE, Amos RS. Sulphasalazine in rheumatoid arthritis: desensitising the patient with a skin rash. Ann Rheum Dis 1986; 45:139-40.

17 Mielsen $\mathrm{OH}$. Sulfasalazine intolerance: a retrospective survey of the reasons for discontinuing treatment with sulfasalazine in patients with chronic inflammatory disease. Scand $\mathcal{f}$ Gastroenterol 1982;17:389-93.

18 Schneider R, Beeley L. Megaloblastic anaemia associated with sulphasalazine treatment. Br Med f $1977 ; i: 1638$.

19 Grindulis KA, McConley B. Does sulphasalazine cause folate deficiency in rheumatoid arthritis? Scand f Rheumatol 1985;14:265-70.

(Accepted 16 fuly 1986)

\title{
Contribution of inappropriate treatment for hypertension to pathogenesis of stroke in the elderly
}

\author{
P A F JANSEN, F W J GRIBNAU, B P M SCHULTE, E F J POELS
}

\begin{abstract}
One hundred and seventy eight patients admitted to hospital with acute cerebral infarction or transient ischaemic attack were studied to determine if their treatment had been changed during the previous three weeks and to compare their blood pressure after the stroke with premorbid values. Blood pressure measurements taken within one year before the stroke were available for 100 patients; seven of these had had a recent change in antihypertensive or diuretic treatment. Of these, three patients who had started taking frusemide because of hypertension and one whose dosage of a reserpine combination drug had been increased experienced an appreciable decrease in blood pressure immediately after the stroke; they also showed signs of haemoconcentration. The change in treatment probably contributed to the stroke in these four patients. The other three showed a smaller decrease or even an increase in blood pressure and no signs of haemoconcentration; the relation between the change in treatment and stroke is less likely in these patients.

The use of high ceiling diuretics such as frusemide in the treatment of hypertension may induce hypovolaemia and hypotension, resulting in cerebral ischaemia, and are therefore best avoided in such treatment.
\end{abstract}

Division of General Internal Medicine, Department of Medicine and Division of Clinical Pharmacology and Pharmacokinetics, Laboratory of Pharmacology, and Institute of Neurology, Catholic University of Nijmegen, PO Box 9101, 6500 HB Nijmegen, The Netherlands

P A F JANSEN, MD, internist

F W J GRIBNAU, MD, professor of clinical pharmacology

B P M SCHULTE, MD, professor of neurology

Department of Neurology, Canisius-Wilhelmina Hospital, Nijmegen, The Netherlands

E F J POELS, MD, neurologist

Correspondence to: Dr Jansen.

\section{Introduction}

Increased blood pressure, especially systolic hypertension, is associated with an increased risk of stroke in people aged over $60 .^{1.5}$ Other studies, including one by the European Working Party on High Blood Pressure in the Elderly, have shown that treatment for hypertension in the elderly reduces cardiovascular and cerebrovascular mortality and morbidity, ${ }^{6-9}$ particularly non-fatal cerebrovascular events. ${ }^{6}$ Treatment for hypertension may prevent the recurrence of stroke, ${ }^{10}{ }^{11}$ especially cerebral haemorrhage,${ }^{12}$ but this effect in the elderly is less certain. ${ }^{13}{ }^{14}$ Nevertheless, treatment for hypertension in the elderly should be considered, though there is no consensus about the diastolic or systolic pressure above which treatment should be given.

Stroke as a paradoxical side effect of treatment for hypertension has been reported. ${ }^{1522} \mathrm{We}$ previously sent a questionnaire to all medical directors of Dutch nursing homes $(n=322)$ asking for information on patients who suffered a stroke shortly after the start of antihypertensive or diuretic treatment. Thirty patients were reported $^{23}$; complete blood pressure measurements were available for nine of them. They had all had an appreciable decrease in blood pressure immediately after the stroke. To establish whether inappropriate antihypertensive or excessively drastic diuretic treatment causes such events, and if so how often, we studied patients admitted to hospital with transient ischaemic attack or acute cerebral infarction to determine if there had been any change in treatment during the three weeks preceding admission and to measure blood pressure immediately after the event and compare it with premorbid values.

\section{Patients and methods}

We studied 178 consecutive patients with cerebral infarction or transient ischaemic attack admitted to the neurology department of a community hospital. In the emergency department a medical history was taken, including drugs being taken, and a standard physical and neurological examination was performed. Blood pressure was measured with a sphygmomanometer, and an electrocardiogram was recorded. Blood was collected for 
measuring, among other things, potassium concentration and haematocrit. In the neurology department blood pressure was measured again, also with a sphygmomanometer, and a computerised tomography scan was performed to distinguish between infarction and haemorrhage.

When infarction or transient ischaemic attack was diagnosed by a neurologist according to the World Health Organisation criteria, ${ }^{24}$ information on the patient's medical history was collected. The patient's general practitioner was asked by telephone for premorbid blood pressure values; he was also asked about any change in the patient's treatment during the three weeks before the event and about the medical history, especially hypertension, diabetes mellitus, and vascular disease. If no blood pressure data were available for the past year the patient was excluded from the study.

Eventually a series of 100 patients remained, in whom the percentage change in mean arterial pressure after the stroke $(\triangle M A P)$ was determined from the following equation:

$$
\triangle \mathrm{MAP}=\frac{\mathrm{MAP}_{\mathrm{A}}-\mathrm{MAP}_{\mathrm{B}}}{\mathrm{MAP}_{\mathrm{B}}} \times 100 \%
$$

where $\mathrm{MAP}_{\mathrm{A}}=$ mean arterial pressure after the stroke (mean of the two measurements taken in the emergency and neurology departments) and $\mathrm{MAP}_{\mathrm{B}}=$ last arterial pressure measured by the general practitioner before the stroke. In both cases mean arterial pressure was defined as the diastolic pressure plus one third of the difference between the systolic and diastolic pressures.

\section{Results}

In 100 patients blood pressure had been measured within one year before admission (mean: five months; range: two days to one year). Table I shows the clinical and laboratory data on these patients. Of the 47 patients known by their doctors to suffer from hypertension according to the criteria of the WHO, ${ }^{25} 38(81 \%)$ were receiving treatment. Two of the 23 patients with diabetes mellitus were dependent on insulin. Of all the 100 patients, 21 had a haematocrit value greater than 0.46 (range $0 \cdot 46-0.56$ ).

\begin{tabular}{lr} 
TABLE I-Clinical and laboratory data on patients included in study \\
\hline M:F & $40: 60$ \\
Age (years) & $74 \cdot 1(8 \cdot 5)$ \\
Mean (SD) & $51-91$ \\
Range & \\
Medical history (No of patients): & 47 \\
Hypertension & 23 \\
Diabetes mellitus & 8 \\
Myocardial infarction & 7 \\
Angina pectoris & 5 \\
Carotid artery pathology & 5 \\
Previous stroke & 4 \\
Hyperlipidaemia & 75 \\
Heart rhythm (No of patients): & 24 \\
Sinus & 1 \\
Atrial fibrillation & \\
2:1 block & $4 \cdot 0(0 \cdot 4)$ \\
Blood chemistry: & $0 \cdot 43(0 \cdot 05)$ \\
Mean (SD) potassium concentration $(\mathrm{mmol} / \mathrm{l})$ & \\
Haematocrit value &
\end{tabular}

Table II lists the diagnoses and localisations of infarction and transient ischaemic attack. Cerebral infarction was diagnosed in 88 patients and transient ischaemic attack in 12 . In 16 patients the treatment had been changed during the previous three weeks (table III): 12 had started treatment with new drugs (frusemide as well as triamterene in one), two had had their dosages increased, and three had stopped taking drugs (one patient had stopped taking acenocoumarol and had started taking frusemide).

TABLE II-Diagnosis and localisation of stroke in 100 patients included in study

\begin{tabular}{lcc}
\hline Artery affected & $\begin{array}{c}\text { Cerebral infarction } \\
(\mathbf{n}=\mathbf{8 8})\end{array}$ & $\begin{array}{c}\text { Transient ischaemic } \\
\text { attack }(\mathbf{n}=12)\end{array}$ \\
\hline Left middle cerebral & 38 & 5 \\
Right middle cerebral & 37 & 6 \\
Left and right middle cerebral & 2 & 1 \\
Basilar & 6 & \\
Posterior & 3 & \\
Anterior & 2 & \\
\hline
\end{tabular}

TABLE III-Changes in treatment during three weeks preceding stroke in 100 patients included in study

\begin{tabular}{lccc}
\hline Drug & Started & $\begin{array}{c}\text { Dose } \\
\text { increased }\end{array}$ & Stopped \\
\hline $\begin{array}{l}\text { Frusemide } \\
\text { Acetosal and dipyridamol }\end{array}$ & 5 & 1 & 1 \\
$\begin{array}{l}\text { Acenocoumarol } \\
\text { Triamterene }\end{array}$ & 3 & & 1 \\
$\begin{array}{l}\text { Isosorbide dinitrate } \\
\text { Haloperidol } \\
\text { Penicillin } \\
\text { Reserpine-dihydralazine-hydrochlorothiazide }\end{array}$ & 1 & & $1^{\star}$ \\
\hline
\end{tabular}

^These patients also started taking frusemide.

The figure shows the changes in mean arterial pressure after infarction and transient ischaemic attack. Mean arterial pressure increased in 71 patients and decreased in 29 . The marked bars in the figure indicate the patients who started or increased their dosage of anti-hypertensive or diuretic treatment during the previous three weeks; table IV shows the data on these seven patients. For illustration one case history (case 6) is presented.

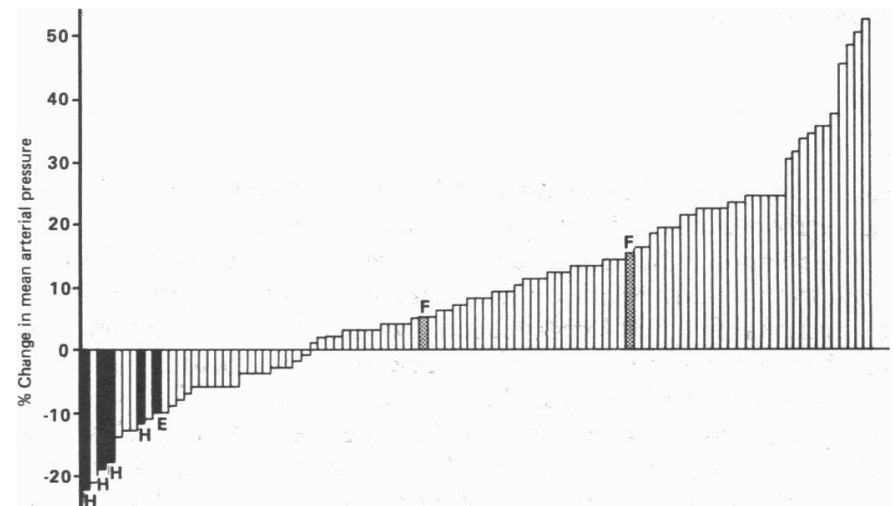

Percentage change in mean arterial pressure $(\triangle M A P)$ in 100 patients admitted with stroke. Black bars represent five patients whose treatment was changed because of oedema $(\mathrm{E})$ and hypertension $(\mathrm{H})$; dotted bars represent two patients whose treatment was changed because of heart failure $(\mathrm{F})$.

Case history-A 72 year old woman had no history of pre-existing hypertension, congestive heart failure, or diabetes mellitus and was not receiving any treatment but sometimes complained of dizziness. The general practitioner had been called to her home because she was confused and had lost vision in her right eye and loss of strength in one hand. On his arrival the neurological signs had disappeared but because of her blood pressure of $190 / 115 \mathrm{~mm} \mathrm{Hg}$ frusemide (40 mg daily) was started. After two days she complained of a constant dizziness and was dysphasic; on admission she had right sided hemianopsia and paralysis of the right arm and leg. Pulsations of the carotid arteries were normal without bruits, an electrocardiogram showed a sinus rhythm, and haematocrit was $0 \cdot 48$. A cerebral computed tomography scan showed infarction in the left occipital area. On admission her blood pressure was $160 / 90 \mathrm{~mm} \mathrm{Hg}$; the decrease in mean arterial pressure was $19 \%$.

\section{Discussion}

Cerebral ischaemia occurring as a side effect of treatment for hypertension has been reported previously. ${ }^{1523}$ In our study seven of 100 patients had important changes in antihypertensive or diuretic treatment during the three weeks before their stroke. We believe that these changes caused a decrease in blood pressure and an increase in the haematocrit value that contributed to the stroke in four patients. We realise that the blood pressures used in this study are based on few measurements and that the blood pressures before the stroke, all recorded by the general practitioner, had led to the decision to start treatment for hypertension or to increase the dose. Side effects of such treatment are better studied prospectively, but we consider it unethical to start incorrect treatment to determine 
TABLE IV-Medical history and clinical data from seven patients who started or increased antihypertensive or diuretic treatment three weeks before stroke

\begin{tabular}{|c|c|c|c|c|c|c|c|c|c|c|}
\hline \multirow[b]{2}{*}{$\begin{array}{l}\text { Case } \\
\text { No }\end{array}$} & \multirow[b]{2}{*}{$\begin{array}{l}\text { Age }(y r s) \\
\operatorname{sex}\end{array}$} & \multirow[b]{2}{*}{ Treatment } & \multirow{2}{*}{$\begin{array}{l}\text { New drug } \\
\text { or dose } \\
\text { increase } \\
\text { (period) }\end{array}$} & \multirow[b]{2}{*}{ Indication } & \multicolumn{2}{|c|}{ Blood pressure $(\mathrm{mm} \mathrm{Hg})$} & \multirow[b]{2}{*}{$\underset{(\%)}{\triangle M A P}$} & \multirow{2}{*}{$\begin{array}{c}\text { Heart } \\
\text { rate } \\
\text { (beats/min) } \\
\text { and rhythm }\end{array}$} & \multirow[b]{2}{*}{ Haematocrit } & \multirow[b]{2}{*}{ Diagnosis } \\
\hline & & & & & $\begin{array}{l}\text { Before } \\
\text { treatment }\end{array}$ & $\begin{array}{c}\text { After } \\
\text { stroke* }\end{array}$ & & & & \\
\hline 1 & $\begin{array}{l}81 / \\
M\end{array}$ & Digoxin and insulin & $\begin{array}{l}\text { Frusemide } \\
\quad(80 \mathrm{mg})(10 \text { days })\end{array}$ & $\begin{array}{l}\text { Congestive heart } \\
\text { failure }\end{array}$ & $150 / 80$ & $155 / 100$ & +15 & $\begin{array}{c}104 \\
\text { Sinus }\end{array}$ & 0.41 & $\begin{array}{l}\text { Infarction, left } \\
\text { middle cerebral } \\
\text { artery }\end{array}$ \\
\hline 2 & $\begin{array}{l}75 / \\
M\end{array}$ & $\begin{array}{l}\text { (Acenocoumarol stopped } \\
\text { one week ago) }\end{array}$ & $\begin{array}{l}\text { Frusemide } \\
\quad 40 \mathrm{mg} \text { ( } 1 \text { day) }\end{array}$ & $\begin{array}{l}\text { Congestive heart } \\
\text { failure }\end{array}$ & $210 / 110$ & $220 / 115$ & +5 & $\begin{array}{c}112 \\
\text { Sinus }\end{array}$ & 0.38 & $\begin{array}{l}\text { Infarction, right } \\
\text { middle cerebral } \\
\text { artery }\end{array}$ \\
\hline 3 & $\begin{array}{l}69 / \\
M\end{array}$ & $\begin{array}{l}\text { Sulphonylurea, salbutamol, } \\
\text { and frusemide } \\
\text { (40 mg twice weekly) }\end{array}$ & $\begin{array}{l}\text { Frusemide } \\
40 \mathrm{mg} \text { once daily } \\
\text { (10 days) }\end{array}$ & Oedema & $120 / 90$ & $130 / 70$ & -10 & $\begin{array}{c}150 \\
\text { Atrial } \\
\text { fibrillation }\end{array}$ & 0.33 & $\begin{array}{l}\text { Infarction, left } \\
\text { middle cerebral } \\
\text { artery }\end{array}$ \\
\hline 4 & $\stackrel{79 /}{\mathrm{F}}$ & $\begin{array}{l}\text { Reserpine-dihydralazine- } \\
\text { hydrochlorothiazide } \\
\text { (once daily) }\end{array}$ & $\begin{array}{l}\text { Twice daily } \\
\text { (6 days) }\end{array}$ & Hypertension & $220 / 130$ & $193 / 115$ & -12 & $\begin{array}{c}88 \\
\text { Sinus }\end{array}$ & $0 \cdot 48$ & $\begin{array}{l}\text { Infarction, left } \\
\text { middle cerebral } \\
\text { artery }\end{array}$ \\
\hline 5 & $\stackrel{67 /}{F}$ & Metoprolol and digoxin & $\begin{array}{l}\text { Frusemide } 40 \mathrm{mg} \\
\text { on alternate } \\
\text { days ( } 17 \text { days })\end{array}$ & Hypertension & $170 / 115$ & $150 / 90$ & -18 & $\begin{array}{c}76 \\
\text { Atrial } \\
\text { fibrillation }\end{array}$ & 0.51 & $\begin{array}{l}\text { Infarction, right } \\
\text { middle cerebral } \\
\text { artery }\end{array}$ \\
\hline 6 & F & & $\begin{array}{l}\text { Frusemide } 40 \mathrm{mg} \\
\text { ( } 2 \text { days })\end{array}$ & Hypertension & $190 / 115$ & $160 / 90$ & -19 & $\begin{array}{c}68 \\
\text { Sinus }\end{array}$ & 0.48 & $\begin{array}{l}\text { Infarction, } \\
\text { posterior } \\
\text { cerebral artery }\end{array}$ \\
\hline 7 & $\begin{array}{l}72 / \\
M\end{array}$ & $\begin{array}{l}\text { Methyldopa and } \\
\text { glibenclamide }\end{array}$ & $\begin{array}{l}\text { Frusemide } 40 \mathrm{mg} \text { and } \\
\text { triamterene once } \\
\text { daily ( } 7 \text { days) }\end{array}$ & Hypertension & $160 / 110$ & $140 / 78$ & -22 & $\begin{array}{c}92 \\
\text { Sinus }\end{array}$ & 0.52 & $\begin{array}{l}\text { Infarction, left } \\
\text { middle cerebral } \\
\text { artery }\end{array}$ \\
\hline
\end{tabular}

^Mean of two values.

severe side effects. We therefore felt obliged to confine ourselves to this retrospective study, despite its shortcomings.

The relation between change in treatment and stroke is difficult to prove in this study because risk factors for stroke were present in all the patients: five had hypertension, two had atrial fibrillation, one had had a transient ischaemic attack two days before complete stroke, two had diabetes mellitus, and one (case 2) had stopped taking acenocoumarol one week before the event. Nevertheless, we believe that in cases $4,5,6$, and 7 the change in treatment at least contributed to the pathogenesis of the stroke. In cases 1,2 , and 3 the relation between treatment and stroke is less likely because of the lack of signs of haemoconcentration, the increase in blood pressure (cases 1 and 2), the cessation of treatment with acenocoumarol in case 2 , and the uncontrolled atrial fibrillation in case 3 .

In our opinion the elderly are especially at risk of cerebral ischaemia from reduced blood pressure for several reasons. Firstly, the baroreflex is less sensitive in old people and a quick decrease in blood pressure cannot be compensated immediately as in the young. ${ }^{26}$ Secondly, cerebral autoregulation may be impaired in the elderly. ${ }^{27}$ The brain is protected from fluctuations in blood pressure by autoregulation. When blood pressure decreases the cerebral vessels dilate; when blood pressure increases they constrict, resulting in a constant cerebral blood flow at mean arterial pressures ranging from 60 to $150 \mathrm{~mm} \mathrm{Hg}$ in normal subjects. The brain of patients with chronic hypertension is more vulnerable to hypotension because the cerebral autoregulatory curve shifts to the right; in these patients a reduction of cerebral blood flow occurs at a higher mean arterial pressure than in normotensive subjects. ${ }^{28} \mathrm{~A}$ reduction in mean arterial pressure of about $25 \%$ is required to reach the lower limit of cerebral blood flow autoregulation; a further reduction to about $55 \%$ is needed to cause symptoms of brain hypoperfusion in both hypertensive patients and normotensive subjects aged under $66 .{ }^{29}$ In 1956 an inverse correlation was shown between cerebral blood flow and age, with a pressure reduction of about $25 \%$ in the elderly compared with the young. ${ }^{30}$ This finding was later confirmed by other authors using more modern methods. ${ }^{3132}$ Thirdly, cerebral blood flow has a lower pressure with a high haematocrit value (over 0.46 ), ${ }^{33}$ though regulatory mechanisms can maintain normal cerebral oxygen transport despite increased viscosity of plasma and whole blood. ${ }^{34}$

Atherosclerosis might be considered important in decreasing the flexibility of arteries in the brain, patients with the most pronounced arteriosclerosis being most at risk of stroke in the event of a hypotensive episode. Several studies, however, do not support this concept. ${ }^{33} 36$ Torvik and Skullerud studied 115 cases of cardiac arrest and found no correlation between the degree of arteriosclerosis and the risk of brain infarcts as a complication of the hypotensive episode ${ }^{36}$ There is a relation between the morphological substrate and the outcome of a period of hypotension, as shown by the neuropathological observations of 11 patients by Adams et $a l^{37}$; the necrosis of grey and white matter at the boundary zones (watersheds) seemed to be attributable to a precipitate reduction in systemic blood pressure while diffuse alterations seemed to be the result of a moderate but sustained systemic hypotension.

For these reasons and because the elderly are more likely to suffer side effects ${ }^{38}{ }^{39}$ blood pressure should be reduced gradually and treatment started with a small dose of relatively safe antihypertensive agent. Primary treatment for hypertension in the elderly is generally with a thiazide diuretic. ${ }^{39}$ Inappropriate antihypertensive treatment may cause stroke: powerful high ceiling diuretics such as frusemide may induce hypovolaemia and hypotension, resulting in cerebral ischaemia. In the treatment of hypertension these drugs are best avoided.

\section{References}

1 Kannel WB, Wolf PA, Verter J, McNamara PM. Epidemiologic assessment of the role of blood pressure in stroke: the Framingham study. FAMA 1970;214:301-10.

2 Kannel WB, Wolf PA, McGee DL, Dawber TR, McNamara P, Castelli WP. Systolic blood pressure, arterial rigidity, and risk of stroke: the Framingham study. fAMA 1981;245:1225-9. Shekelle RB, Ostfeld AM, Klawans HL. Hypertension and risk of stroke in an elderly population. Stroke 1974;5:71-5.

Forette F, de la Fuente X, Golmard JL, Henry JF, Hervy MP. The prognostic significance of isolated systolic hypertension in the elderly. Results of a ten longitudinal survey. Clin Exp Hypertens 1982;(A4)7:1177-9

5 Colandrea MA, Friedman GD, Nichaman MZ, Lynd CN. Systolic hypertension in the elderly. An epidemiological assessment. Circulation 1970;41:239-45.

6 Amery A, Birkenhäger W, Brixko $P$, et al. Mortality and morbidity results from the European Working Party on high blood pressure in the elderly trial. Lancet 1985;i:1349-54.

7 Veterans Administration Cooperative Study Group on Antihypertensive Agents. Effects of treatment on morbidity in hypertension. III. Influence of age, diastolic pressure and prior cardiovascular disease; further analysis of side effects. Circulation 1972;45:991-1004.

8 Hypertension Detection and Follow-up Program Cooperative Group. Five year findings of the hypertension detection and follow-up program. II. Mortality by race, sex and age. FAMA $1979 ; 242: 2572-7$

9 Report by the Management Committee. The Australian therapeutic trial in mild hypertension. Lancet 1980;i:1261-7.

10 Marshall J. A trial of long-term hypotensive therapy in cerebrovascular disease. Lancet 1964;i:

10-2.
11 Beevers DG, Fairman MJ, Hamilton M, Harpur JE. Antihypertensive treatment and the course of established cerebral vascular disease. Lancet 1973;i:1407-9.

12 Black DG. Heagerty AM, Bing RF, Thurston H, Swales JD. Effects of treatment for hypertension on cerebral haemorrhage and infarction. BrMed f 1984;289:156-9.

13 Hypertension-Stroke Cooperative Study Group. Effect of antihypertensive treatment on stroke recurrence. $\mathcal{F} A M A$ 1974;229:409-18.

14 Carter AB. Hypotensive therapy in stroke survivors. Lancet 1970;i:485-9.

\section{豪}


15 Graham DI. Ischaemic brain damage of cerebral perfusion failure type after treatment of severe hypertension. BrMed f 1975;ii:739.

16 Jackson G, Mahon W, Pierscianowski TA, Condon J. Inappropriate antihypertensive therapy in the elderly. Lancet 1976;ii:1317-8.

17 Cove DH, Seddon M, Fletcher RF, Dukes DC. Blindness after treatment for malignant hypertension. Br Med f 1979;ii:245-6.

18 Ledingham JGG, Rajagopalan B. Cerebral complications in the treatment of accelerated hypertension. Qf Med 1979;48:25-41.

19 Pitlik S, Manor RS, Lipshitz I, Perry G, Rosenfeld J. Transient retinal ischaemia induced by nifedipine. BrMed $\mathcal{O}$ 1983;287:1845-6.

20 Phillips MS, Jones JV. Emergency treatment of high blood pressure with oral atenolol. Br Med $\mathcal{J}$ $1981 ; 283: 58$.

21 Strandgaard S, Andersen GS, Ahlgreen P, Nielsen PE. Visual disturbances and occipital brain infarct following acute, transient hypotension in hypertensive patients. Acta Med Scand infarct following
$1984 ; 216: 417-22$.

22 Russell RW, Page NGR. Critical perfusion of brain and retina. Brain 1983;106:419-34

23 Jansen PAF, Schulte BPM, Mevboom RHB, Gribnau FWJ. Antihypertensive treatment as a possible cause of stroke in the elderly. Age Ageing 1986;15:129-38.

24 World Health Organisation. Cerebrovascular diseases--prevention, treatment and rehabilitation. WHO Tech Rep Ser 1971:469.

25 World Health Organisation. Arterial hypertension. WHO Tech Rep Ser 1978:628.

26 Gribbin B, Pickering TG, Sleight P, Peto R. Effect of age and high blood pressure on baroreflex sensitivity in man. Circ Res 1971;29:424-31.

27 Wollner L, McCarthy ST, Soper NDW, Macy DJ. Failure of cerebral autoregulation as a cause of brain dysfunction in the elderly. $\mathrm{Br}$ Med $\mathcal{f}$ 1979;i:1117-8.
28 Strandgaard S, Olesen J, Skinhoi $E$, Lassen NA. Autorequlation of brain circulation in severe arterial hypertension. Br Med f 1973;i:507-10.

29 Strandgaard S. Autoregulation of cerebral blood flow in hypertensive patients. The modifying influence of prolonged antihypertensive treatment on the tolerance to acute, drug-induced hypotension. Circulation 1976;53:720-7.

$30 \mathrm{Kety}$ SS. Human cerebral blood flow and oxygen consumption as related to ageing. $\mathcal{F}$ Chronic Dis 1956;3:478-86.

31 Thomas DJ, Zilkha E, Redmond S, et al. An intravenous ${ }^{133}$ xenon-clearance technique for measuring cerebral blood flow. I Neurol Sci 1979;40:53-63

32 Davis SM, Ackerman RH, Correia JA, et al. Cerebral blood flow and cerebrovascular $\mathrm{CO}_{2}$ reactivity in stroke-age normal controls. Neurology 1983;33:391-9.

33 Thomas DJ, Marshall J, Russell RW, et al. Effect of haematocrit on cerebral blood-flow in man. Lancet 1977;ii:941-3.

34 Brown MM, Marshall J. Regulation of cerebral blood flow in response to changes in blood viscosity. Lancet 1985; ;:604-9.

35 Kendell RE, Marshall J. Role of hypotension in the genesis of transient focal cerebral ischaemic attacks. BrMed 7 1963;ii:344-8.

36 Torvik A, Skullerud K. How often are brain infarcts caused by hypotensive episodes? Stroke 1976;7:255-7.

37 Adams JH, Brierley B, Connor RCR, Treip CS. The effects of systemic hypotension upon the human brain, clinical and neuropathological observations in 11 cases. Brain 1966;89:235-80.

38 Hurwitz H. Predisposing factors in adverse reactions to drugs. Br Med F 1969;i:536-9.

39 Williams BO. Use and misuse of diuretics in the elderly. Prescribers fournal 1985;25:51-6.

(Accepted 11 fuly 1986)

\title{
Determinants and importance of stress hyperglycaemia in non-diabetic patients with myocardial infarction
}

\author{
G A OSWALD, C C T SMITH, D J BETTERIDGE, J S YUDKIN
}

\begin{abstract}
Determinants of plasma glucose concentrations were studied in patients on admission to hospital with confirmed acute myocardial infarction but without previous glucose intolerance as evidenced by raised concentrations of glycosylated haemoglobin $\left(\mathbf{H b A}_{\mathrm{lc}}\right)$. Mortality in hospital increased significantly with increasing plasma concentrations of glucose in patients with both normal $(\mathbf{p}<0.0001, n=311)$ and borderline $(\mathbf{p}<0.02, n=70)$ concentrations of $\mathbf{H b A}_{\mathrm{lc}}$. There was a weak relation between plasma glucose concentrations and infarct size as estimated by peak aspartate transaminase activity in both $\mathbf{H b A}_{\mathrm{lc}}$ groups $\left(\mathbf{r}_{\mathbf{s}}=\right.$ $0.26, n=101$ and $r_{s}=0.41, n=35$ respectively). A correlation was found between adrenaline and plasma glucose concentrations $(r=0.47, n=27)$ and cortisol and plasma glucose concentrations $(r=0.75, n=19)$, but the relation of plasma noradrenaline and plasma glucose suggested a threshold effect. Concentrations of adrenaline, but not those of noradrenaline or cortisol, correlated with infarct size as measured both by peak aspartate transaminase activity and cumulative release of creatine kinase MB isoenzyme. Multiple regression analysis showed that concentrations of cortisol, adrenaline, and noradrenaline (but not the concentration of $\mathbf{H b A}_{\mathrm{lc}}$, infarct size, or age) are the main determinants of plasma glucose concentration measured in non-diabetic patients when admitted to hospital after acute myocardial infarction.
\end{abstract}

Academic Unit of Diabetes and Endocrinology, University College and Middlesex School of Medicine, Whittington Hospital, London N19 5NF G A OSWALD, MD, MRCP, research fellow in diabetes

J S YUDKIN, MD, MRCP, consultant and senior lecturer in diabetes

Department of Medicine of the University College and Middlesex School of Medicine, London WC1E 6JJ

C C T SMITH, MSC, PHD, research fellow and honorary lecturer in biochemistry D J BETTERIDGE, PHD, MRCP, senior lecturer

Correspondence and requests for reprints to: Dr Yudkin.

\section{Introduction}

The reasons for excessive mortality in diabetic patients with acute myocardial infarction remain undetermined. The potentially reversible metabolic disequilibriums that accompany acute myocardial infarction in diabetics may be responsible, ${ }^{1}$ although this is a difficult hypothesis to test. ${ }^{2}$ A relation has, however, been described in patients with acute myocardial infarction between hyperglycaemia on admission and the development of cardiogenic shock independent of the state of premorbid glucose tolerance. ${ }^{3}$ Thus hyperglycaemia alone might possibly contribute to poor outcome in patients both with and without known diabetes. We tested this hypothesis in non-diabetic patients, in whom other factors peculiar to diabetes mellitus which may contribute to outcome after acute myocardial infarction, such as the existence of a specific diabetic heart muscle disease ${ }^{4}$ or abnormal rheology, ${ }^{5}$ are not present. The interrelations of hyperglycaemia on admission to hospital, infarct size, hormonal response to stress, and outcome in a group of patients with acute myocardial infarction, but without evidence of premorbid undiagnosed diabetes, were investigated

\section{Methods \\ The study group consisted of 397 patients, without known diabetes mellitus, admitted consecutively to the Whittington Hospital with acute myocardial infarction confirmed by the World Health Orgnisation's criteria. ${ }^{6}$ Figure 1 shows the design of the study and composition of the patient subgroups. In all patients venous blood was taken immediately or shortly after their admission for determining concentrations of $\mathrm{HbA}_{\mathrm{lc}}$. Patients were classified as previously described ${ }^{3}$ into clearly normal (group $1, \mathrm{HbA}_{\mathrm{lc}}<6.9 \%$ ), borderline (group 2, $\mathrm{HbA}_{\mathrm{lc}} 6 \cdot 9-7 \cdot 8 \%$ ), or clearly abnormal (group 3, $\mathrm{HbA}_{\mathrm{lc}}>7 \cdot 8 \%$ ) groups. Seventeen patients had concentrations of $\mathrm{HbA}_{\mathrm{tc}}$ falling into group 3 , which we have found to be indicative of undiagnosed diabetes, ${ }^{36 a}$ and were considered no further.}

STUDY 1: RELATION BETWEEN PLASMA GLUCOSE AND HBA ${ }_{\mathrm{lc}}$ CONCENTRATIONS AND OUTCOME

Of the 380 patients without diabetes, samples for plasma glucose measurement were taken from 236 on their admission to hospital before 